\title{
Lei Fang* and Cara McDaniel Home hours in the United States and Europe
}

DOI 10.1515/bejm-2015-0031

Previously published online July 9, 2016

\begin{abstract}
Using data from the Multinational Time Use Study, this paper documents the trend and level of time allocation, with a focus on home hours, for the US and European countries. Three patterns emerge. First, home hours per person have declined in both the US and European countries over the past 50 years. Second, female time allocation contributes more to the difference in time allocation per person between the US and European countries than does male time allocation. Third, the time allocation between the US and European countries is more similar for prime-age individuals than for young and old individuals.
\end{abstract}

Keywords: age; gender; home hours; time use.

JEL Classification: J22; D13.

\section{Introduction}

Based on field research, Kahneman and Krueger (2006) find that different activities of everyday life provide different levels of happiness. Hence, studying the time allocation for different activities is important. As a subcategory of time allocation, market work has been studied extensively in the literature. By contrast, studies on home work are limited due to a lack of data availability until recently. ${ }^{1}$ The allocation of time for home activities is not only interesting in itself but also important in facilitating the understanding of market activities. ${ }^{2}$ Indeed, one stream in the literature has demonstrated that the inclusion of home production improves the performance of standard models in accounting for business

1 Recent papers that examine home hours include Aguiar and Hurst (2007), Ramey and Francis (2009), Ramey (2009), Freeman et al. (2005), Burda, Hamermesh, and Weil (2008), Ragan (2013), Ngai and Pissarides (2011), and Gimenez-Nadal and Sevilla (2012).

2 Alexopoulos and Cavalcanti (2010) find that home production is also important in understanding the problem of the persistence of inequality.

\footnotetext{
*Corresponding author: Lei Fang, Research Department, Federal Reserve Bank of Atlanta, 1000 Peachtree St. NE, Atlanta, GA 30309, USA, e-mail: Lei.fang@atl.frb.org Cara McDaniel: Department of Economics, Arizona State University, AZ, USA
} 
cycle fluctuation. ${ }^{3}$ Another stream in the literature finds that home production is important in accounting for the market labor supply difference between the US and Europe..$^{4}$ In light of the importance of home work, this paper studies the trend and level of home hours for the US and European countries.

We construct measures of home work, market work, and total work in each decade from the 1960s to the 2000s using the data from the Multinational time use study (MTUS). We find that the core home hours (i.e. household work, such as cooking, cleaning, and laundry) have declined in both the US and European countries since the 1960s. Americans spend the least amount of time on core home work than other nationals in all five decades. ${ }^{5}$ Over the sample period, men have generally decreased their market hours and increased their home hours, whereas women in all countries have increased their market hours and decreased their home hours. This shift leads to a significant reduction in the gender gap in market hours and home hours. We also find that the time that men and women devote to their children has increased in most of the countries studied.

More importantly, we find that cross-country differences in time allocation are largely driven by the time allocation decision of women. This finding is established from the following observations. First, the cross-country dispersion in female market hours is much larger than the dispersion in male market hours. Second, the declining trend in home hours per person is entirely driven by the decline in female home hours because male home hours have increased in all countries. Third, the countries with larger declines in home hours per person generally have larger declines in female home hours. Fourth, the cross-country difference in home hours is larger for women than it is for men in the 2000s.

We also examine time allocation by age group. Home hours have declined across all age groups in all of countries studied. Men of all age groups have increased their home hours, and women of all age groups have decreased their home hours. Hence, the decline in female home hours also drives the decline in home hours per person for each age group. Furthermore, we find that the time allocation of all three categories, namely, home work, market work, and total work, are more similar for the prime-age group than for the young and old groups between the US and European countries. The reason is mainly the employment to population ratio is more similar for the prime-age group between the US and European countries. We also find that, across countries, decades, and genders,

3 For examples, see Greenwood and Hercowitz (1991), Benhabib, Rogerson, and Wright (1991), McGrattan, Rogerson, and Wright (1997), and Campbell and Ludvigson (2001).

4 For examples, see Greenwood and Hercowitz (1991), Benhabib, Rogerson, and Wright (1991), McGrattan, Rogerson and Wright (1997), and Campbell and Ludvigson (2001).

5 The Netherlands in the 1970s is an exception. 
young individuals spend less time and old individuals spend more time on home production than do prime-age individuals. Finally, total work has declined for all age groups of both genders. The smallest and largest declines are found for the prime-age group and the young group, respectively.

\subsection{Related literature}

This paper is closely related to the literature on the documentation of time allocations. Ramey (2009) and Bianchi et al. (2000) find that home hours in the US have declined over time. Ramey and Francis (2009) find that leisure in the US has increased. Aguiar and Hurst (2007) construct measures of time allocation for the US and focus on how leisure has changed within demographic groups. ${ }^{6}$ Sevilla, Gimenez-Nadal, and Gershuny (2012) study the trend in the quality of leisure for the US. All five of these papers study time allocation for the US. Several other studies examine time allocation in multiple countries. Freeman et al. (2005) study time allocation for the US and a few European countries in the early 1990s. Ragan (2013) and Ngai and Pissarides (2011) study more countries, but their analysis is only for the 2000s. Burda, Hamermesh, and Weil (2008) and Burda, Hamermesh, and Weil (2013) examine total work by gender for a group of countries. These papers, which study time allocation in both the US and Europe, focus on only recent periods, and therefore, they have no trend implications.

Following Aguiar and Hurst (2007), Gimenez-Nadal and Sevilla (2012) construct data for several industrialized countries other than the United States, but their focus is primarily on how leisure changes over time for different demographic groups within a country. By contrast, we focus on analyzing the trend and level differences in home hours between the US and European countries. We also demonstrate that the cross-country differences in time allocation are largely driven by the cross-country differences in the time allocation of women and nonprime-age individuals.

We find that both men and women have increased the time they spend on child care in the countries studied. This finding is consistent with Bianchi (2000), Sayer, Bianchi and Robinson (2004), Ramey and Ramey (2010), and Gauthier, Smeeding and Furstenberg (2004). ${ }^{7}$ The first three papers find that the time spent

6 The web Appendix D compares our estimates for the US to estimates from Aguiar and Hurst (2007).

7 Guryan, Hurst, and Kearney (2008) find that more educated parents spend more time with their children. 
on child care has increased in the US and the last paper finds that the time spent on child care has increased in a group of industrialized countries.

The decline in female home hours is closely related to the increase in the female labor force participation rate. The literature has found that factors such as improvement in the home production productivity [Greenwood, Seshadri, and Yorukoglu (2005), Cavalcanti and Tavares (2008), and Greenwood, Guner, and Vandenbroucke (Forthcoming)], increases in the supply of government services [Cavalcanti and Tavares (2011)], changes in social norms [Fogli and Veldkamp (2011) and Fernandez (2013)], and gender-biased demand shift [Galor and Weil (1996), Heathcote, Storesletten, and Violante (2010), and Ngai and Petrongolo (2014)] are all important in accounting for the rise in the female labor force participation rate and therefore the decline in female home hours. ${ }^{8}$

This paper is also related to the literature that attempts to account for the difference in market hours between the US and Europe using models with home production [Ragan (2013), Rogerson (2008), Ngai and Pissarides (2008), Ngai and Pissarides (2011), and McDaniel (2011)]. In principle, a successful model should generate predictions for both market and home hours that are consistent with the data. Our constructed home hours are useful in this regard because our estimates can be used to calibrate and evaluate the theoretical models.

The rest of the paper is organized as follows. Section 2 discusses the data and methodology. Section 3 presents our estimates. Section 4 concludes.

\section{Data}

\subsection{Data and methodology}

We use data from the Multinational Time Use Study (MTUS) to construct our estimates of time allocation. The MTUS is an ongoing project with the intent of harmonizing the time use data collected by different statistical agencies in different countries. Because the project is ongoing, there are different releases of the time use data. When possible, we use the most recent release. ${ }^{9}$ Table 1 presents the country name, year, and number of observations for each survey included in our sample. The details for each survey are available in the web Appendix F.

8 Goldin (1990) and Costa (2000) summarize the various factors behind the rise in married female labor force participation rate.

9 The estimates in this paper come from the W5.0, W55.2, W55.3, and W6.0 releases. 
Table 1: MTUS countries and years.

\begin{tabular}{crrr}
\hline Survey & Observations & Survey & Observations \\
\hline France & & Norway & \\
$1966^{*}$ & 2898 & 1971 & 5467 \\
$1974^{*}$ & 4633 & 1981 & 3966 \\
1998 & 12,388 & 1990 & 19,997 \\
Germany & & 1995 & 19,740 \\
$1965^{*}$ & 2137 & 2000 & 10,346 \\
1991 & 21,792 & United Kingdom & \\
2001 & 27,318 & 1974 & 14,372 \\
Italy & & 1981 & 3966 \\
$1979 *$ & 2116 & 1990 & 5266 \\
1989 & 13,027 & 1995 & 19,740 \\
2002 & 35,571 & 2000 & 13,346 \\
Netherlands & & 2005 & 3622 \\
1975 & 7803 & United States & \\
1980 & 16,350 & 1965 & 1948 \\
1985 & 19,462 & 1975 & 1949 \\
1990 & 19,997 & 1985 & 2539 \\
1995 & 19,740 & 1992 & 6556 \\
2000 & 10,346 & 2003 & 38,511 \\
2005 & 12,335 & 2005 & 21,004 \\
\hline
\end{tabular}

*5.0 release, ages $20-59$ only.

The MTUS dataset contains diary entries in which each respondent reports the time spent on standard activities. Each entry also contains information on the date, day of the week, and demographic characteristics of the respondent. In surveys in which a diarist records activities on multiple days, each diary entry is treated as unique. We divide the data by age group (15-19, 20-24, 25-34, 35-44, 45-54, 55-59, and 60-64), gender, and labor market status (active/inactive). We then calculate the average hours per week spent on each activity for each demographic group..$^{10}$

Because the surveyed population may not reflect the composition of the actual population, we construct weights based on gender, age and labor market status and

10 Several surveys are only available in the release of the 5.0 format. This release includes only individuals aged 20-59. For the results reported in the main text, we assume that the members of the 15-19 age group spend the same number of weekly hours on each activity as their demographic counterparts in the 20-24 age group. We use the same procedure for individuals aged $60-64$ but use the 55-59 age group as the reference group. We make a similar assumption if only part of an age group is available. In the web Appendix E, we examine two alternative scenarios to construct the estimates. The results are close to those reported in the paper. 
calculate the weighted average of the time spent on each activity using the constructed weights. We construct the weights from the OECD Labor Force Statistics (whenever available; see the country notes in the web Appendix F). ${ }^{11}$ We also weight the diary observations such that the days of the week are equally represented across the survey.

Aguiar and Hurst (2007) and Gimenez-Nadal and Sevilla (2012) construct measures of time allocation while holding the demographic composition (age, gender, educational attainment and the presence of children) of the population constant over time. However, demographics are not necessarily similar across countries at a given point in time, and the changes in demographics over time are also not necessarily similar across countries. Thus, although a constant demographic weighting scheme is ideal in studying how different time allocations change across demographic groups within a country, it is not appropriate for comparing time allocations across countries. Specifically, under the constant demographic weighting scheme, the time allocation level does not reflect the actual time allocation level for an average person in a given country and decade. Hence, we cannot compare time allocation levels across countries in a given decade. Furthermore, aggregate data from the Groningen Growth and Development Center (GGDC) show that a large part of the difference in market hours per person between the US and European countries is due to the difference in the employment to population ratio. The MTUS data also show that home hours differ substantially for employed and nonemployed individuals. Hence, it is important to weight the data by labor market status when comparing time allocations between the US and European countries.

\subsection{Activity categories}

To harmonize the time use surveys, the MTUS groups the activities in each individual survey into standard categories. We construct the measures of market work and home work from the 41 standard activity categories. ${ }^{12}$ Table 2 reports each of the 41 activities. We follow the classification of market work and home work by Aguiar and

\footnotetext{
11 Although it may be ideal to construct more detailed demographic groups, a consistent source for constructing weights is not available. Each survey includes suggested survey weights, but we choose not to use these weights because some surveys provide weights only for age groups and others for finer categories.

12 The most recent MTUS releases contain two sets of activity categories: a set of 41 activities and a set of 69 more narrowly defined activities. The 69-activity typology is not available for all of the countries studied. Thus, we must use the 41 activity codes. However, we are able to use the 69-activity typology when comparing our results for the US with those of Aguiar and Hurst (2007) in the web Appendix D. We also demonstrate how the estimates change for the US when we switch to the 41-activity typology.
} 
Table 2: MTUS activities.

\begin{tabular}{|c|c|c|c|}
\hline \multicolumn{2}{|c|}{ Core market work } & \multicolumn{2}{|c|}{ Leisure continued } \\
\hline AV 1 & Paid work, primary job & AV 19 & Active sports participation \\
\hline AV 2 & Paid work at home & AV 20 & Passive sports participation \\
\hline AV 3 & Paid work, second job & AV 21 & Walking \\
\hline \multicolumn{2}{|c|}{ Total market work $=$ core +} & AV 22 & Religious activities \\
\hline AV 5 & Travel to/from work & AV 23 & Civic activities \\
\hline \multicolumn{2}{|c|}{ Core non-market } & AV 24 & Cinema or theater \\
\hline AV 6 & Cook, wash up & AV 25 & Dances or parties \\
\hline AV 7 & Housework & AV 26 & Social clubs \\
\hline \multicolumn{2}{|c|}{ Shopping } & AV 27 & Pubs \\
\hline AV 10 & Shopping & AV 28 & Restaurants \\
\hline AV 12 & Domestic travel & AV 29 & Visit friends at their homes \\
\hline \multicolumn{2}{|c|}{ Total non-market $=$ core + shopping +} & AV 30 & Listen to radio \\
\hline AV 8 & Odd jobs & AV 31 & Watch television or video \\
\hline AV 9 & Gardening & AV 32 & Listen to records, tapes, cds \\
\hline \multicolumn{2}{|c|}{ Childcare } & AV 33 & Study, homework \\
\hline AV 11 & Childcare & AV 34 & Read books \\
\hline \multicolumn{2}{|l|}{ Leisure } & AV 35 & Read papers, magazines \\
\hline AV 4 & School, classes & AV 36 & Relax \\
\hline AV 13 & Dress/personal care & AV 37 & Conversation \\
\hline AV 14 & Consume personal services & AV 38 & Entertain friends at home \\
\hline AV 15 & Meals and snacks at home & AV 39 & Knit, sew \\
\hline AV 16 & Sleep & AV 40 & Other leisure \\
\hline AV 17 & Free time travel & AV 41 & Unclassified time \\
\hline AV 18 & Excursions & & \\
\hline
\end{tabular}

Hurst (2007) as closely as possible. We separate market work into "core" and "total" categories. Core market work includes work for pay at a primary job with paid meals and breaks included, work for pay at a second job, and work for pay at home. ${ }^{13}$ The total market hours are the sum of the core market hours and the commuting time.

Following Aguiar and Hurst (2007), we define two measures for home work: core home work and total home work. ${ }^{14}$ Core home work includes cooking, doing dishes, cleaning, laundry, and mending. In addition to core home work, total home work includes purchasing goods and services, running errands (e.g. going to the post office, picking up the dry cleaning, etc.), gardening, and "odd jobs" (e.g. home and vehicle repair and pet care). We also create a separate category for

13 Time spent on the job search is included in the work-from-home category in the MTUS. The entire work-from-home category represents a negligible share of the core market work.

14 The patterns for home work reported in the next section also hold for the measure of "core home work+shopping hours" and the measure of "total home work+child care." 
child care. Child care includes the time spent on the care of children and infants and the time spent on obtaining their medical care. ${ }^{15}$

Based on the measures for market work and home work, we also define two categories of total work, which is defined as the sum of market work and home work. Core total work is the sum of core market work and core home work. Total work is the sum of total market work and total home work. The residual of total work is considered leisure. Aguiar and Hurst (2007) analyze the trend in leisure for the United States, and Gimenez-Nadal and Sevilla (2012) analyze the trend in leisure for a few industrialized countries; thus, we do not analyze the trend in leisure in this paper.

\section{Time allocation}

This section discusses the constructed data. The estimates are reported as hours per week spent on each time allocation category. We report the estimates by decade. ${ }^{16}$ For most countries, there is only one survey (if any) in a given decade. When there is more than one survey in a decade (e.g. for the Netherlands, 1980 and 1985), the estimates are reported as the average of the surveys in this decade. We also report the changes in weekly hours between the 2000s and the 1960s and the 1970s. The time series patterns and the cross-sectional patterns are similar for the "core" and "total" measures of time allocation. For this reason, we only report and discuss the estimates for core market work, core home work, and core total work. The estimates for the "total" measures of time allocation are available in the web Appendix G. ${ }^{17}$

\subsection{Market hours}

\subsubsection{Market hours per person}

The cross-country differences in market hours per person have been well documented using the aggregate data from the GGDC. ${ }^{18}$ Table 3 reports our constructed

\footnotetext{
15 The time spent preparing meals for children and taking care of their clothing is included in core home work.

16 The latest year that the survey is available for France is 1998, the results for which are reported under the "2000s" category in the tables.

17 The web Appendix G also reports the measure of "total work+child care.” The pattern for this measure is similar to the pattern for core total work.

18 See, for example, Ohanian, Raffo and Rogerson (2008).
} 
Table 3: Core market work.

\begin{tabular}{|c|c|c|c|c|c|c|c|}
\hline & \multicolumn{5}{|c|}{ Average hours per week } & \multicolumn{2}{|c|}{ Change $2000 \mathrm{~s}$} \\
\hline & $1960 \mathrm{~s}$ & 1970s & $1980 \mathrm{~s}$ & $1990 \mathrm{~s}$ & $2000 s$ & $1960 s$ & $1970 \mathrm{~s}$ \\
\hline \multicolumn{8}{|l|}{ All } \\
\hline France & 29.2 & 24.6 & & & 22.9 & -6.3 & -1.7 \\
\hline Germany & 31.4 & & & 25.9 & 19.7 & -11.7 & \\
\hline Italy & & 23.9 & 22.9 & & 22.0 & & -1.9 \\
\hline Netherlands & & 17.8 & 15.5 & 17.2 & 23.9 & & 6.1 \\
\hline Norway & & 24.2 & 24.9 & 23.7 & 25.1 & & 0.9 \\
\hline UK & & 24.9 & 22.5 & 25.5 & 24.8 & & -0.1 \\
\hline USA & 28.6 & 26.5 & 26.4 & 27.9 & 27.2 & -1.4 & 0.8 \\
\hline \multicolumn{8}{|l|}{ Men } \\
\hline France & 40.9 & 34.5 & & & 28.3 & -12.6 & -6.2 \\
\hline Germany & 44.4 & & & 34.1 & 25.6 & -18.8 & \\
\hline Italy & & 34.7 & 32.2 & & 30.4 & & -4.3 \\
\hline Netherlands & & 27.0 & 24.3 & 25.4 & 31.4 & & 4.4 \\
\hline Norway & & 35.8 & 32.2 & 30.2 & 30.7 & & -5.1 \\
\hline UK & & 36.8 & 29.5 & 32.0 & 30.6 & & -6.2 \\
\hline USA & 41.8 & 36.6 & 33.1 & 33.4 & 32.5 & -9.3 & -4.1 \\
\hline \multicolumn{8}{|l|}{ Women } \\
\hline France & 17.6 & 14.9 & & & 17.6 & 0.0 & 2.7 \\
\hline Germany & 18.7 & & & 17.5 & 13.7 & -5.0 & \\
\hline Italy & & 13.5 & 13.8 & & 13.6 & & 0.1 \\
\hline Netherlands & & 8.5 & 6.9 & 8.8 & 16.3 & & 7.8 \\
\hline Norway & & 12.3 & 17.6 & 17.1 & 19.3 & & 7.0 \\
\hline UK & & 13.2 & 15.5 & 19.2 & 18.9 & & 5.7 \\
\hline USA & 16.3 & 17.0 & 20.1 & 22.4 & 22.0 & 5.7 & 5.0 \\
\hline
\end{tabular}

Columns under "Change 2000s" report the change in weekly hours over the period 1960 s or 1970s-2000s.

data for core market hours per person. The observations from the table are broadly consistent with the observations from the aggregate data. Specifically, the market hours in France and Germany were larger than those in the US in the 1960s and have decreased sharply ever since. By contrast, the weekly market hours per person in the US have not changed much. Because of the difference in the trend movement, in the 2000s, the market hours per person in European countries were lower than those in the US.

The cross-country differences in market hours are smaller in our data compared to those constructed from the GGDC data. The GGDC estimates are adjusted for paid vacations, holidays, and sick time, whereas the time use data are not adjusted. Because Europeans enjoy more paid time off, estimates from the time use data necessarily underestimate the differences in market hours between the 
US and European countries. In the web Appendix C, we provide comparisons between our estimates and the estimates from the GGDC data.

\subsubsection{Market hours by gender}

Table 3 also reports the weekly market hours by gender. Consistent with the studies for the US by McGrattan and Rogerson (2004), Ramey and Francis (2009), and Aguiar and Hurst (2007) and studies for other countries by Gimenez-Nadal and Sevilla (2012), the market hours per male have declined and the market hours per female have increased in most countries, with the exceptions of male hours in the Netherlands and female hours in Germany.

In the 1960s, both men and women in France and Germany worked no less than their counterparts in the US. By contrast, in the 2000s, both men and women worked more in the US than in European countries. More importantly, the cross-country differences in market hours are smaller for men than for women. Specifically, the cross-country dispersion in market hours, as measured by the coefficient of variation, ${ }^{19}$ is larger for women than for men in every decade. The average over the five decades is 0.09 for men and is 0.2 for women. ${ }^{20}$ The larger cross-country difference in market hours per female implies that female market hours contribute more to the cross-country variations in market hours per person.

\subsubsection{Market hours by age}

Next, we study market hours across age groups. Table 4 reports the trend change in market hours by age group. Core market hours have declined for both the young and the old groups in all countries except the Netherlands. Men of all ages have generally decreased their market hours. Prime-age women have increased their market hours in all countries. Young and old women have increased their market hours in some countries but have decreased their market hours in others.

Table 5 reports the levels of market hours by age group. Prime-age men in every country work the highest number of hours in all five decades. Prime-age

19 The coefficient of variation is defined as the standard deviation normalized by the mean.

20 The coefficient of variation for core market hours by decade from the 1960s to the 2000s, respectively, is $0.04,0.11,0.11,0.10$, and 0.07 for men and $0.06,0.22,0.30,0.27$, and 0.17 for women. 
Table 4: Change in core market work by age.

\begin{tabular}{|c|c|c|c|c|c|c|c|c|}
\hline & \multicolumn{4}{|c|}{ Change 1960s-2000s } & \multicolumn{4}{|c|}{ Change 1970s-2000s } \\
\hline & $15-24$ & $25-54$ & $55-64$ & Total & $15-24$ & $25-54$ & $55-64$ & Total \\
\hline \multicolumn{9}{|l|}{ All } \\
\hline France & -12.9 & -3.6 & -15.0 & -6.3 & -9.1 & 1.3 & -10.8 & -1.7 \\
\hline Germany & -23.8 & -7.7 & -13.2 & -11.7 & & & & \\
\hline Italy & & & & & -9.5 & -0.1 & -3.6 & -1.9 \\
\hline Netherlands & & & & & -0.0 & 9.0 & 2.5 & 6.1 \\
\hline Norway & & & & & -4.6 & 2.6 & -2.4 & 0.9 \\
\hline UK & & & & & -3.1 & 1.2 & -4.3 & -0.1 \\
\hline USA & -6.6 & 0.3 & -5.1 & -1.4 & -4.0 & 1.1 & 0.6 & 0.8 \\
\hline \multicolumn{9}{|l|}{ Men } \\
\hline France & -15.0 & -11.8 & -22.6 & -12.6 & -11.3 & -4.9 & -15.3 & -6.2 \\
\hline Germany & -25.7 & -16.0 & -24.3 & -18.8 & & & & \\
\hline Italy & & & & & -11.0 & -3.3 & -8.3 & -4.3 \\
\hline Netherlands & & & & & -0.4 & 5.5 & 1.3 & 4.4 \\
\hline Norway & & & & & -6.4 & -4.9 & -9.5 & -5.1 \\
\hline UK & & & & & -7.4 & -5.6 & -11.7 & -6.2 \\
\hline USA & -14.4 & -7.5 & -15.3 & -9.3 & -8.8 & -4.5 & -3.8 & -4.1 \\
\hline \multicolumn{9}{|l|}{ Women } \\
\hline France & -10.7 & 4.9 & -7.8 & 0.0 & -6.8 & 7.7 & -6.9 & 2.7 \\
\hline Germany & -21.9 & -0.0 & -4.2 & -5.0 & & & & \\
\hline Italy & & & & & -7.4 & 2.3 & -0.2 & 0.1 \\
\hline Netherlands & & & & & 0.4 & 12.7 & 2.8 & 7.8 \\
\hline Norway & & & & & -2.4 & 10.5 & 4.3 & 7.0 \\
\hline UK & & & & & 0.8 & 8.0 & 2.0 & 5.7 \\
\hline USA & 0.9 & 7.6 & 3.0 & 5.7 & 0.5 & 6.2 & 3.8 & 5.0 \\
\hline
\end{tabular}

Values are changes in average hours per week.

women work the highest number of hours in the 2000s relative to young and older women in the same period but fewer hours than young women in European countries in earlier periods. More importantly, in every decade, market hours are more similar across countries for the prime-age group than for the young and old groups. In particular, in the 2000s, the cross-country difference in market hours is much larger for the old group than for the prime-age group. Specifically, the average of market hours for old Europeans is $40 \%$ ( 9 hours) less than the US value, and the average of market hours for prime-age Europeans is only $12 \%$ (3.6 hours) less than the US value. The cross-country variation is also larger for the old group. Old Europeans work as much as $45 \%-89 \%$ of their American counterparts, and prime-age Europeans work as much as 79\%-94\% of their American counterparts. 


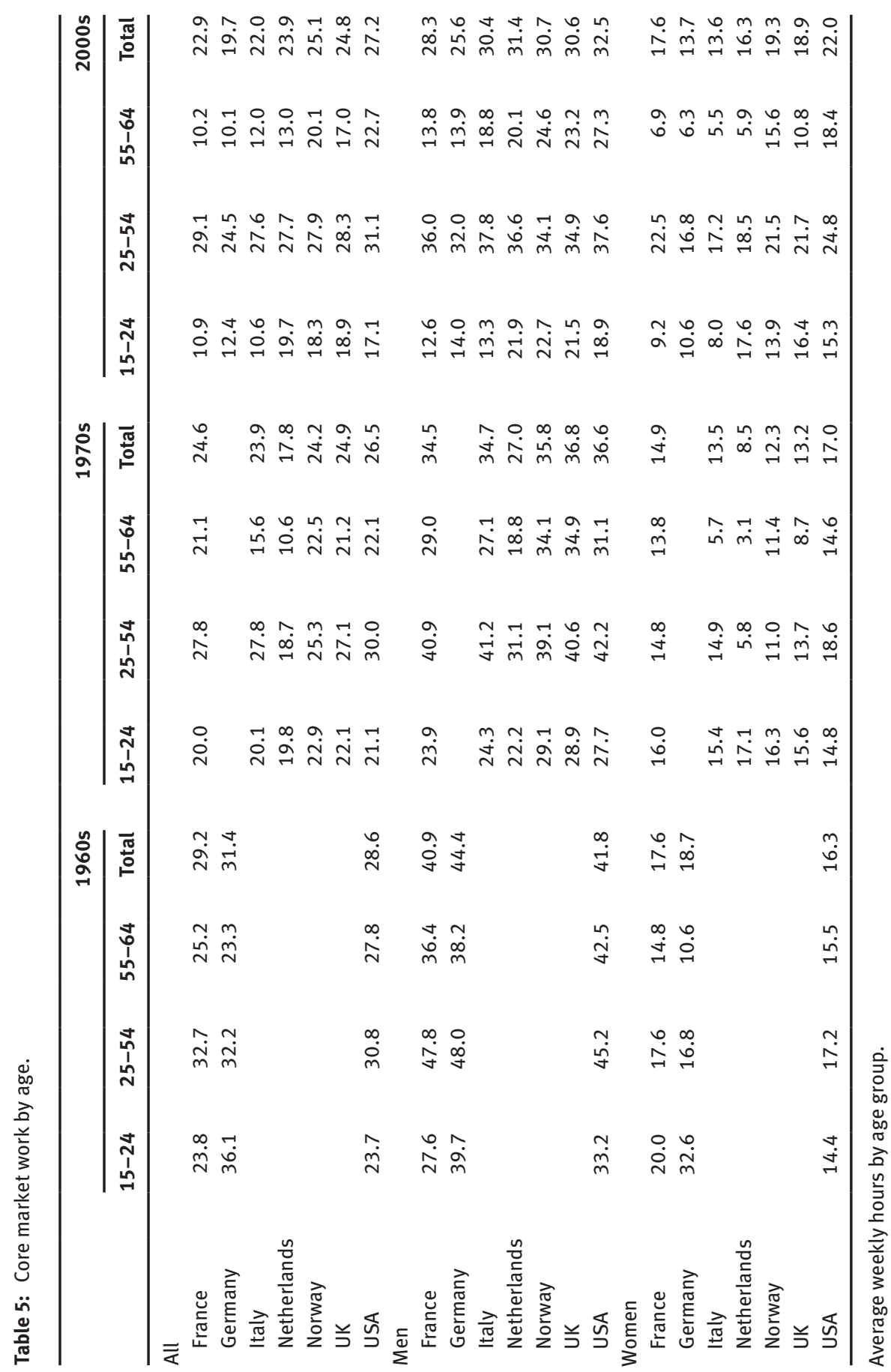




\subsection{Home hours}

\subsubsection{Home hours per person}

This section examines the estimated home hours per person. Table 6 reports the estimates for core home hours per person. We start the analysis with the observation that core home hours per person have declined in all countries over this period of time. Core home hours in the United States decreased by 5.2 hours between the 1960s and the 2000s and by 3.6 hours between the 1970s and the 2000s. ${ }^{21}$ The average decline in core home hours in European countries is 4 hours

Table 6: Core home work.

\begin{tabular}{|c|c|c|c|c|c|c|c|}
\hline & \multicolumn{5}{|c|}{ Average hours per week } & \multicolumn{2}{|c|}{ Change 2000s } \\
\hline & $1960 s$ & 1970s & $1980 s$ & $1990 \mathrm{~s}$ & $2000 s$ & $1960 s$ & 1970s \\
\hline \multicolumn{8}{|l|}{ All } \\
\hline France & 15.3 & 15.3 & & & 11.3 & -4.0 & -4.0 \\
\hline Germany & 14.3 & & & 9.8 & 10.4 & -3.9 & \\
\hline Italy & & 15.6 & 15.9 & & 14.1 & & -1.5 \\
\hline Netherlands & & 11.5 & 11.5 & 10.1 & 8.9 & & -2.6 \\
\hline Norway & & 16.6 & 12.3 & 9.6 & 11.5 & & -5.1 \\
\hline UK & & 12.1 & 11.9 & 10.7 & 10.1 & & -2.0 \\
\hline USA & 13.5 & 11.9 & 9.8 & 8.4 & 8.3 & -5.2 & -3.6 \\
\hline \multicolumn{8}{|l|}{ Men } \\
\hline France & 3.5 & 4.3 & & & 4.1 & 0.6 & -0.2 \\
\hline Germany & 1.4 & & & 4.0 & 5.1 & 3.7 & \\
\hline Italy & & 2.2 & 1.9 & & 3.2 & & 1.0 \\
\hline Netherlands & & 2.9 & 3.9 & 4.3 & 4.5 & & 1.6 \\
\hline Norway & & 3.9 & 4.8 & 4.3 & 7.4 & & 3.5 \\
\hline UK & & 2.4 & 5.0 & 4.9 & 5.5 & & 3.1 \\
\hline USA & 2.7 & 3.0 & 4.4 & 4.7 & 4.6 & 1.9 & 1.6 \\
\hline \multicolumn{8}{|l|}{ Women } \\
\hline France & 27.0 & 26.2 & & & 18.3 & -8.7 & -7.9 \\
\hline Germany & 26.3 & & & 15.7 & 15.8 & -10.5 & \\
\hline Italy & & 28.7 & 29.5 & & 25.1 & & -3.6 \\
\hline Netherlands & & 20.2 & 19.2 & 16.0 & 13.3 & & -6.8 \\
\hline Norway & & 29.5 & 20.0 & 15.1 & 15.7 & & -13.8 \\
\hline UK & & 21.7 & 18.8 & 16.3 & 14.7 & & -7.0 \\
\hline USA & 23.7 & 20.2 & 15.0 & 12.0 & 12.1 & -11.6 & -8.1 \\
\hline
\end{tabular}

Columns under "Change 2000s" report the change in weekly hours over the period 1960s or 1970s-2000s.

21 Ramey and Francis (2009) and Aguiar and Hurst (2007) also find a decrease in home hours for the US. 
from the 1960s and is 3 hours from the 1970s. In particular, the decline from the 1970s onward is larger in Norway and France than in the United States.

Next, we discuss the cross-country difference in the levels of core home hours. In every decade, Americans spend less time in core home activities than do Europeans..$^{22}$ In the 2000s, core home hours are 70\% (5.8 hours) higher in Italy, $22 \%$ (1.8 hours) higher in Germany and the UK, 7\% (0.6 hour) higher in the Netherlands, and 35\% (3 hours) higher in other countries. Our findings are consistent with the studies by Freeman et al. (2005), Ragan (2013), and Ngai and Pissarides (2011). The former study finds that home hours are higher in Germany than in the US in the early 1990s. The latter two find that home hours are greater in European countries than in the US in the 2000s.

\subsubsection{Home hours by gender}

Table 6 also reports core home hours by gender. The table reveals that women in all countries reduced their core home hours and that men in all countries increased their core home hours. ${ }^{23}$ Hence, the decline in home hours per person is entirely driven by the decline in female home hours in all countries. Because of the opposite trend movement, the gap between male and female home hours has narrowed from an average of 23 hours in the 1960s to an average of 11 hours in the 2000s, with women working more at home in all countries and all years.

More importantly, we find that the countries with a larger decline in core home hours generally display a larger decline in core home hours per female. Specifically, in the countries with a more-than-3-hour decline in core home hours per person between the 1970s and the 2000s (France, Norway, and the US), the average decline in female home hours is 10 hours compared to the average decline in female home hours of 5.8 hours in the other countries. This observation suggests that the cross-country difference in the trend of home hours per female contributes more to the cross-country difference in the trend of home hours per person.

We next explore the level differences in home hours across countries. Table 6 reveals that core home hours per male in the US generally lie in the middle of all of the countries studied and that core home hours per female in the US are always the lowest in every decade. With respect to the magnitude in the 2000s, men in Italy,

22 The Netherlands in 1970 is an exception.

23 Aguiar and Hurst (2007) and Ramey and Francis (2009) find the same pattern for the US and Gimenez-Nadal and Sevilla (2012) find the same pattern for several European countries. 
France, and the Netherlands work less at home than do men in the US, and men in other European countries all work more at home than men do in the US Core home hours per male range from $70 \%$ of the US level (1.4 hours less) in Italy to $161 \%(2.8$ hours more) of the US level in Norway, and the European average is $8 \%$ (0.4 hours) greater than the US level. The cross-country difference in core home hours per female is more pronounced. Core home hours per female range from $110 \%$ of the US level (2 hours more) in the Netherlands to 207\% (13 hours more) of the US level in Italy, and the European average is 42\% (5.1 hours) greater than the US level. This finding demonstrates that the difference in home hours per female also contributes more to the difference in home hours per person in the 2000s.

\subsubsection{Home hours by age}

Table 7 reports the changes in core home hours by age group. Core home hours have declined across all age groups in all countries. Men of all age groups have increased their core home hours except in France. The largest and the smallest increases are generally obtained for old men and young men, respectively. By contrast, in every country, women of all age groups have decreased their core home hours. The largest decrease is generally obtained for prime-age women. The increasing trend for men and the decreasing trend for women of all age groups imply that the female series also drives the aggregate decline in home hours for each age group.

Table 8 reports the average number of home hours per week by age group. Across countries, decades, and genders, young individuals spend less time and old individuals spend more time in home production than prime-age individuals. In addition, in the 2000s, the differences in home hours between the US and European countries are larger for the old age group than for the other age groups. Specifically, average Europeans aged 15-24 work 6\% (0.3 hours) more at home, average Europeans aged 25-54 work 28\% (2.6 hours) more at home, and average Europeans aged 55-64 work 54\% (5.2 hours) more at home than the corresponding age groups in the US.

In summary, this section establishes the common decreasing trend in home hours per person for the countries studied. We demonstrate that the cross-country differences in female market hours and home hours contribute more to the differences in both the trends and the levels of time allocation per person. ${ }^{24}$ We also

24 Freeman et al. (2005) find that there is more variation in the cross-country female time allocation using data on the 1990s. 
Table 7: Change in core home work by age.

\begin{tabular}{|c|c|c|c|c|c|c|c|c|}
\hline & \multicolumn{4}{|c|}{ Change 1960s-2000s } & \multicolumn{4}{|c|}{ Change 1970s-2000s } \\
\hline & $15-24$ & $25-54$ & $55-64$ & Total & $15-24$ & $25-54$ & $55-64$ & Total \\
\hline \multicolumn{9}{|l|}{ All } \\
\hline France & -6.8 & -3.6 & -2.8 & -4.0 & -6.1 & -4.1 & -2.3 & -4.0 \\
\hline Germany & -3.1 & -4.8 & -3.9 & -3.9 & & & & \\
\hline Italy & & & & & -1.4 & -2.9 & -2.5 & -1.5 \\
\hline Netherlands & & & & & -2.7 & -3.6 & -2.4 & -2.6 \\
\hline Norway & & & & & -2.0 & -7.2 & -4.0 & -5.1 \\
\hline UK & & & & & -1.4 & -2.9 & -1.7 & -2.0 \\
\hline USA & -5.0 & -5.4 & -6.1 & -5.2 & -4.9 & -3.4 & -4.0 & -3.6 \\
\hline \multicolumn{9}{|l|}{ Men } \\
\hline France & -0.6 & 1.2 & -0.3 & 0.6 & -0.7 & 0.1 & -1.3 & -0.2 \\
\hline Germany & 1.5 & 3.7 & 5.0 & 3.7 & & & & \\
\hline Italy & & & & & 0.2 & 0.9 & 1.9 & 1.0 \\
\hline Netherlands & & & & & 0.7 & 1.5 & 2.0 & 1.6 \\
\hline Norway & & & & & 1.8 & 3.4 & 5.0 & 3.5 \\
\hline UK & & & & & 1.3 & 3.1 & 4.2 & 3.1 \\
\hline USA & 0.2 & 2.3 & 1.5 & 1.9 & -0.5 & 2.3 & 0.6 & 1.6 \\
\hline \multicolumn{9}{|l|}{ Women } \\
\hline France & -13.5 & -8.6 & -4.2 & -8.7 & -12.1 & -8.5 & -2.8 & -7.9 \\
\hline Germany & -8.1 & -12.1 & -10.1 & -10.5 & & & & \\
\hline Italy & & & & & -3.1 & -6.2 & -5.4 & -3.6 \\
\hline Netherlands & & & & & -6.3 & -9.0 & -5.8 & -6.8 \\
\hline Norway & & & & & -6.0 & -18.0 & -12.2 & -13.8 \\
\hline UK & & & & & -3.9 & -9.0 & -6.8 & -7.0 \\
\hline USA & -10.2 & -12.6 & -11.7 & -11.6 & -9.0 & -8.6 & -8.0 & -8.1 \\
\hline
\end{tabular}

Values are changes in average hours per week.

find that the differences in time allocation are more pronounced for the old-age group than for the prime-age group between the US and European countries.

\subsection{Child care}

Table 9 reports the average hours per week spent on child care-related activities. Both men and women have increased their time spent on child care in almost all countries over the sample period. In addition, as shown in Table 10, most of the increase in child care time for both genders can be attributed to the increase in child care time by prime-age individuals. Indeed, young men and young women have both decreased their child care time in most of the countries studied. This 


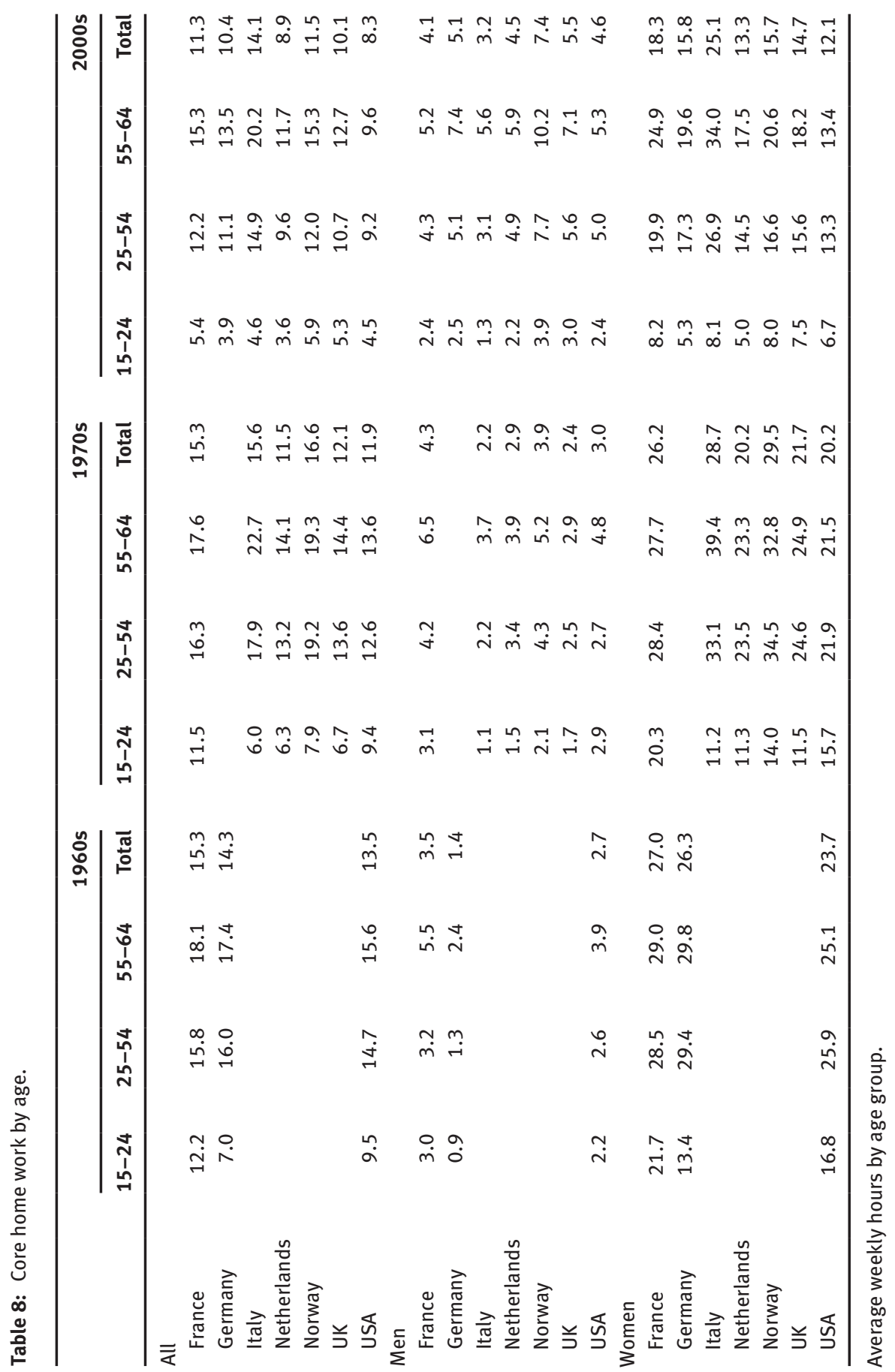


Table 9: Childcare.

\begin{tabular}{|c|c|c|c|c|c|c|c|}
\hline & \multicolumn{5}{|c|}{ Average hours per week } & \multicolumn{2}{|c|}{ Change 2000s } \\
\hline & 1960s & 1970s & $1980 \mathrm{~s}$ & $1990 \mathrm{~s}$ & $2000 \mathrm{~s}$ & $1960 \mathrm{~s}$ & $1970 s$ \\
\hline \multicolumn{8}{|l|}{ All } \\
\hline France & 5.4 & 4.0 & & & 2.7 & -2.7 & -1.3 \\
\hline Germany & 3.3 & & & 3.4 & 3.2 & -0.1 & \\
\hline Italy & & 2.2 & 2.1 & & 2.5 & & 0.3 \\
\hline Netherlands & & 2.6 & 2.8 & 2.9 & 3.0 & & 0.4 \\
\hline Norway & & 2.9 & 3.2 & 3.8 & 3.8 & & 0.9 \\
\hline UK & & 1.6 & 2.5 & 4.0 & 3.8 & & 2.1 \\
\hline USA & 3.1 & 3.0 & 2.3 & 2.1 & 4.6 & 1.5 & 1.6 \\
\hline \multicolumn{8}{|l|}{ Men } \\
\hline France & 1.9 & 1.3 & & & 1.3 & -0.6 & 0.0 \\
\hline Germany & 1.0 & & & 2.0 & 1.9 & 0.9 & \\
\hline Italy & & 1.2 & 1.1 & & 1.3 & & 0.1 \\
\hline Netherlands & & 1.4 & 1.4 & 1.6 & 1.8 & & 0.4 \\
\hline Norway & & 1.2 & 1.9 & 2.2 & 2.1 & & 0.9 \\
\hline UK & & 0.5 & 1.4 & 2.4 & 2.2 & & 1.8 \\
\hline USA & 1.2 & 1.2 & 0.9 & 0.9 & 2.8 & 1.6 & 1.6 \\
\hline \multicolumn{8}{|l|}{ Women } \\
\hline France & 8.8 & 6.7 & & & 4.1 & -4.7 & -2.6 \\
\hline Germany & 5.4 & & & 4.9 & 4.6 & -0.8 & \\
\hline Italy & & 3.2 & 3.1 & & 3.6 & & 0.4 \\
\hline Netherlands & & 3.7 & 4.0 & 4.3 & 4.3 & & 0.6 \\
\hline Norway & & 4.7 & 4.5 & 5.4 & 5.5 & & 0.8 \\
\hline UK & & 2.6 & 3.8 & 5.7 & 5.2 & & 2.6 \\
\hline USA & 5.0 & 4.7 & 3.7 & 3.2 & 6.4 & 1.4 & 1.7 \\
\hline
\end{tabular}

Columns under "Change 2000s" report the change in weekly hours over the period 1960s or 1970s-2000s.

finding is consistent with the pattern of delayed childbearing in the past 50 years. Not surprisingly, Table 11 shows that women and prime-age individuals spend more time on child care in every country and every decade.

\subsection{Total work}

Table 12 reports the weekly hours of core total work. Core total hours have declined except in the Netherlands. In general, the increase in male home hours does not fully compensate for the decline in male market hours, and the increase in female market hours does not fully compensate for the decline in female home hours. As a result, both male and female total work hours have declined. This 
Table 10: Change in childcare by age.

\begin{tabular}{|c|c|c|c|c|c|c|c|c|}
\hline & \multicolumn{4}{|c|}{ Change 1960s-2000s } & \multicolumn{4}{|c|}{ Change 1970s-2000s } \\
\hline & $15-24$ & $25-54$ & $55-64$ & Total & $15-24$ & $25-54$ & $55-64$ & Total \\
\hline \multicolumn{9}{|l|}{ All } \\
\hline France & -5.1 & -2.7 & -0.4 & -2.7 & -4.7 & -0.7 & 0.3 & -1.3 \\
\hline Germany & -2.1 & 0.5 & -0.4 & -0.1 & & & & \\
\hline Italy & & & & & -0.8 & 0.6 & -0.4 & 0.3 \\
\hline Netherlands & & & & & -0.8 & 0.5 & 1.2 & 0.4 \\
\hline Norway & & & & & -0.6 & 1.3 & -0.4 & 0.9 \\
\hline UK & & & & & 1.1 & 2.7 & 0.7 & 2.1 \\
\hline USA & 0.2 & 2.2 & -0.6 & 1.5 & -0.3 & 2.6 & -0.5 & 1.6 \\
\hline \multicolumn{9}{|l|}{ Men } \\
\hline France & -2.0 & -0.4 & 0.2 & -0.6 & -0.9 & 0.1 & -0.1 & 0.0 \\
\hline Germany & -0.7 & 1.7 & -0.2 & 0.9 & & & & \\
\hline Italy & & & & & -0.1 & 0.1 & -0.1 & 0.1 \\
\hline Netherlands & & & & & -0.3 & 0.3 & 0.3 & 0.4 \\
\hline Norway & & & & & -0.3 & 1.3 & -0.2 & 0.9 \\
\hline UK & & & & & 1.0 & 2.2 & 0.5 & 1.8 \\
\hline USA & 0.3 & 2.2 & -0.0 & 1.6 & 0.1 & 2.3 & -0.2 & 1.6 \\
\hline \multicolumn{9}{|l|}{ Women } \\
\hline France & -8.2 & -5.0 & -0.9 & -4.7 & -8.6 & -1.6 & 0.7 & -2.6 \\
\hline Germany & -3.7 & -0.3 & -0.6 & -0.8 & & & & \\
\hline Italy & & & & & -1.7 & 1.1 & -0.6 & 0.4 \\
\hline Netherlands & & & & & -1.4 & 0.5 & 2.1 & 0.6 \\
\hline Norway & & & & & -0.9 & 1.1 & -0.6 & 0.8 \\
\hline UK & & & & & 1.4 & 3.2 & 1.0 & 2.6 \\
\hline USA & 0.2 & 2.1 & -1.3 & 1.4 & -0.7 & 3.0 & -0.8 & 1.7 \\
\hline
\end{tabular}

Values are changes in average hours per week.

finding suggests that, although both men and women reallocate their time from the market to the home and vice versa, they are also allocating more time to other activities, mainly leisure. Despite the large difference in market hours and home hours between the two genders, men and women have a similar number of total hours for most of the available surveys, which is consistent with the finding by Burda, Hamermesh, and Weil (2008) for the 2000s.

The changes in market hours and home hours provide insights into the sources of the change in total work. In Germany and Italy, the decline in total work is largely driven by the decline in market work; in France, although the decline in total work relative to the 1960s is roughly divided in half, the decline relative to the 1970s is largely driven by the decline in home work; in the United States, Norway, and the United Kingdom, the decline in total work is primarily 


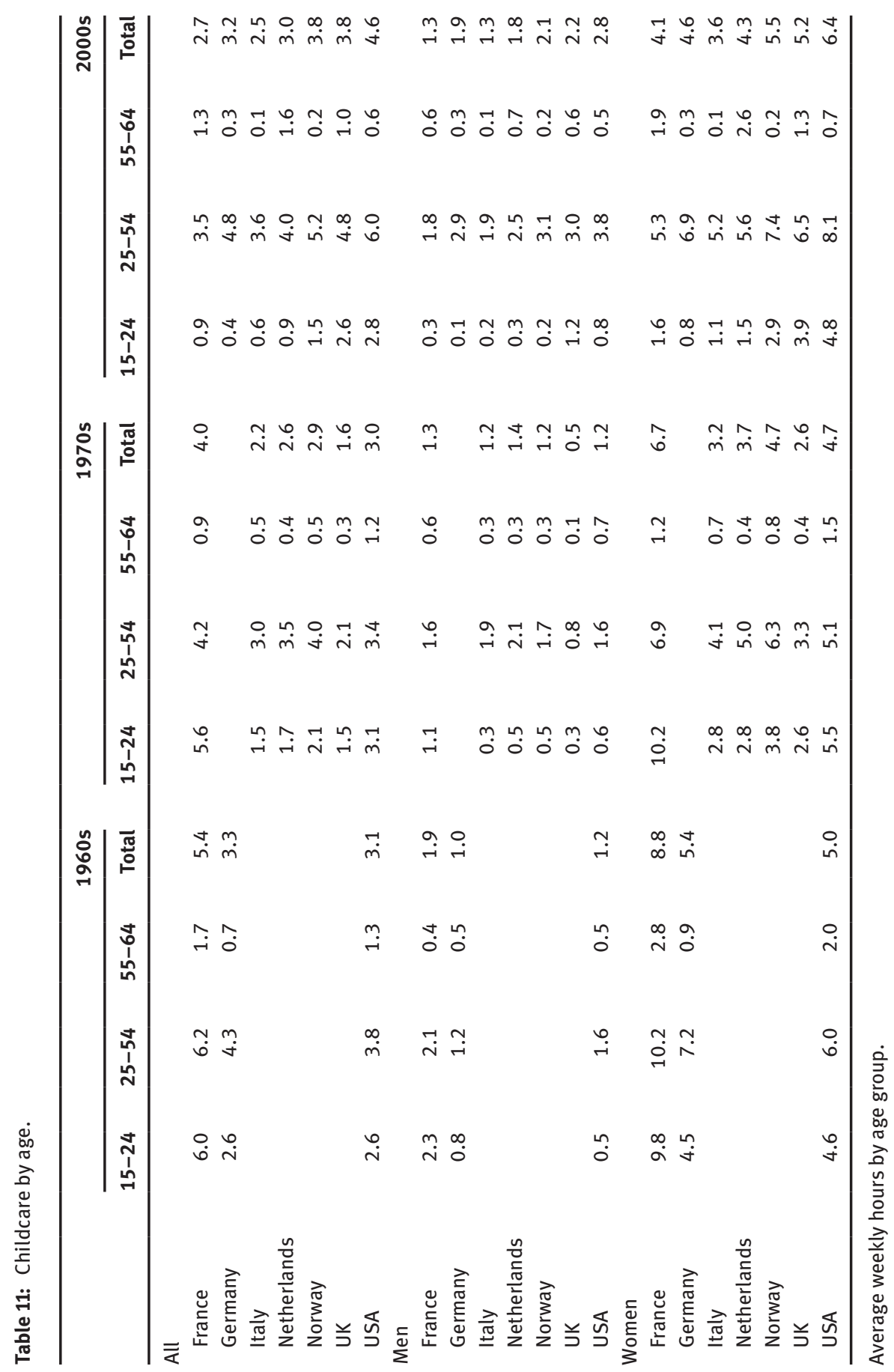


Table 12: Core total work.

\begin{tabular}{|c|c|c|c|c|c|c|c|}
\hline & \multicolumn{5}{|c|}{ Average hours per week } & \multicolumn{2}{|c|}{ Change 2000s } \\
\hline & 1960s & 1970s & $1980 \mathrm{~s}$ & $1990 \mathrm{~s}$ & $2000 s$ & 1960s & $1970 s$ \\
\hline \multicolumn{8}{|l|}{ All } \\
\hline France & 44.5 & 39.9 & & & 34.2 & -10.3 & -5.7 \\
\hline Germany & 45.7 & & & 35.7 & 30.1 & -15.6 & \\
\hline Italy & & 39.5 & 38.8 & & 36.2 & & -3.3 \\
\hline Netherlands & & 29.3 & 27.1 & 27.3 & 32.8 & & 3.5 \\
\hline Norway & & 40.8 & 37.2 & 33.4 & 36.6 & & -4.2 \\
\hline UK & & 37.0 & 34.4 & 36.2 & 34.8 & & -2.2 \\
\hline USA & 42.2 & 38.3 & 36.2 & 36.3 & 35.5 & -6.7 & -2.8 \\
\hline \multicolumn{8}{|l|}{ Men } \\
\hline France & 44.4 & 38.8 & & & 32.4 & -12.0 & -6.4 \\
\hline Germany & 45.9 & & & 38.0 & 30.7 & -15.2 & \\
\hline Italy & & 36.8 & 34.1 & & 33.7 & & -3.1 \\
\hline Netherlands & & 29.9 & 28.1 & 29.7 & 35.9 & & 6.0 \\
\hline Norway & & 39.7 & 37.0 & 34.5 & 38.2 & & -1.5 \\
\hline UK & & 39.2 & 34.5 & 36.9 & 36.0 & & -3.2 \\
\hline USA & 44.6 & 39.7 & 37.5 & 38.1 & 37.0 & -7.6 & -2.7 \\
\hline \multicolumn{8}{|l|}{ Women } \\
\hline France & 44.6 & 41.1 & & & 36.0 & -8.6 & -5.1 \\
\hline Germany & 45.0 & & & 33.2 & 29.5 & -15.5 & \\
\hline Italy & & 42.2 & 43.3 & & 38.7 & & -3.5 \\
\hline Netherlands & & 28.7 & 26.1 & 24.9 & 29.6 & & 0.9 \\
\hline Norway & & 41.8 & 37.6 & 32.2 & 35.0 & & -6.8 \\
\hline UK & & 34.9 & 34.3 & 35.6 & 33.6 & & -1.3 \\
\hline USA & 40.0 & 37.2 & 35.1 & 34.4 & 34.1 & -5.9 & -3.1 \\
\hline
\end{tabular}

Columns under "Change 2000s" report the change in weekly hours over the period 1960 s or 1970s-2000s.

driven by the decline in home work; and in the Netherlands, the increase in total work is driven by the increase in market work, whereas a decline in home work is observed.

Table 13 reports the change in core total work by age group. Core total work has declined for all age groups for both genders. ${ }^{25}$ Prime-age individuals of both genders have the smallest decline in all countries, and young individuals have the largest decline in most countries. Table 14 reports the levels of core total work by age group. Prime-age men and women work the most, and young men and

25 The Netherlands is an exception. 
Table 13: Change in core total work by age.

\begin{tabular}{|c|c|c|c|c|c|c|c|c|}
\hline & \multicolumn{4}{|c|}{ Change 1960s-2000s } & \multicolumn{4}{|c|}{ Change 1970s-2000s } \\
\hline & $15-24$ & $25-54$ & $55-64$ & Total & $15-24$ & $25-54$ & $55-64$ & Total \\
\hline \multicolumn{9}{|l|}{ All } \\
\hline France & -19.8 & -7.1 & -17.7 & -10.3 & -15.3 & -2.8 & -13.1 & -5.7 \\
\hline Germany & -26.9 & -12.5 & -17.0 & -15.6 & & & & \\
\hline Italy & & & & & -10.8 & -3.1 & -6.1 & -3.3 \\
\hline Netherlands & & & & & -2.7 & 5.4 & 0.1 & 3.5 \\
\hline Norway & & & & & -6.5 & -4.6 & -6.4 & -4.2 \\
\hline UK & & & & & -4.6 & -1.8 & -6.0 & -2.2 \\
\hline USA & -11.6 & -5.1 & -11.1 & -6.7 & -8.9 & -2.3 & -3.5 & -2.8 \\
\hline \multicolumn{9}{|l|}{ Men } \\
\hline France & -15.6 & -10.6 & -23.0 & -12.0 & -11.9 & -4.8 & -16.7 & -6.4 \\
\hline Germany & -24.2 & -12.3 & -19.2 & -15.2 & & & & \\
\hline Italy & & & & & -10.8 & -2.4 & -6.5 & -3.1 \\
\hline Netherlands & & & & & 0.4 & 7.0 & 3.3 & 6.0 \\
\hline Norway & & & & & -4.6 & -1.6 & -4.5 & -1.5 \\
\hline UK & & & & & -6.2 & -2.6 & -7.5 & -3.2 \\
\hline USA & -14.2 & -5.2 & -13.8 & -7.6 & -9.3 & -2.3 & -3.2 & -2.7 \\
\hline \multicolumn{9}{|l|}{ Women } \\
\hline France & -24.2 & -3.7 & -11.9 & -8.6 & -18.9 & -0.8 & -9.6 & -5.1 \\
\hline Germany & -29.9 & -12.2 & -14.3 & -15.5 & & & & \\
\hline Italy & & & & & -10.6 & -3.9 & -5.5 & -3.5 \\
\hline Netherlands & & & & & -5.9 & 3.7 & -3.0 & 0.9 \\
\hline Norway & & & & & -8.5 & -7.6 & -8.0 & -6.8 \\
\hline UK & & & & & -3.2 & -1.1 & -4.7 & -1.3 \\
\hline USA & -9.4 & -5.0 & -8.8 & -5.9 & -8.5 & -2.4 & -4.2 & -3.1 \\
\hline
\end{tabular}

Values are changes in average hours per week.

women work the least in all countries and all decades. There is also less crosscountry variation in total work for the prime-age group than there is for the other age groups. In particular, in the 2000s, core total work in European countries ranges from $88 \%$ to $105 \%$ of the US level for the prime-age group, and the corresponding range is $71 \%-112 \%$ for the young group and $74 \%-110 \%$ for the old group.

\subsection{Discussion}

This section compares our estimates and the estimates constructed with the constant demographic weighting scheme. Following Aguiar and Hurst (2007) and 


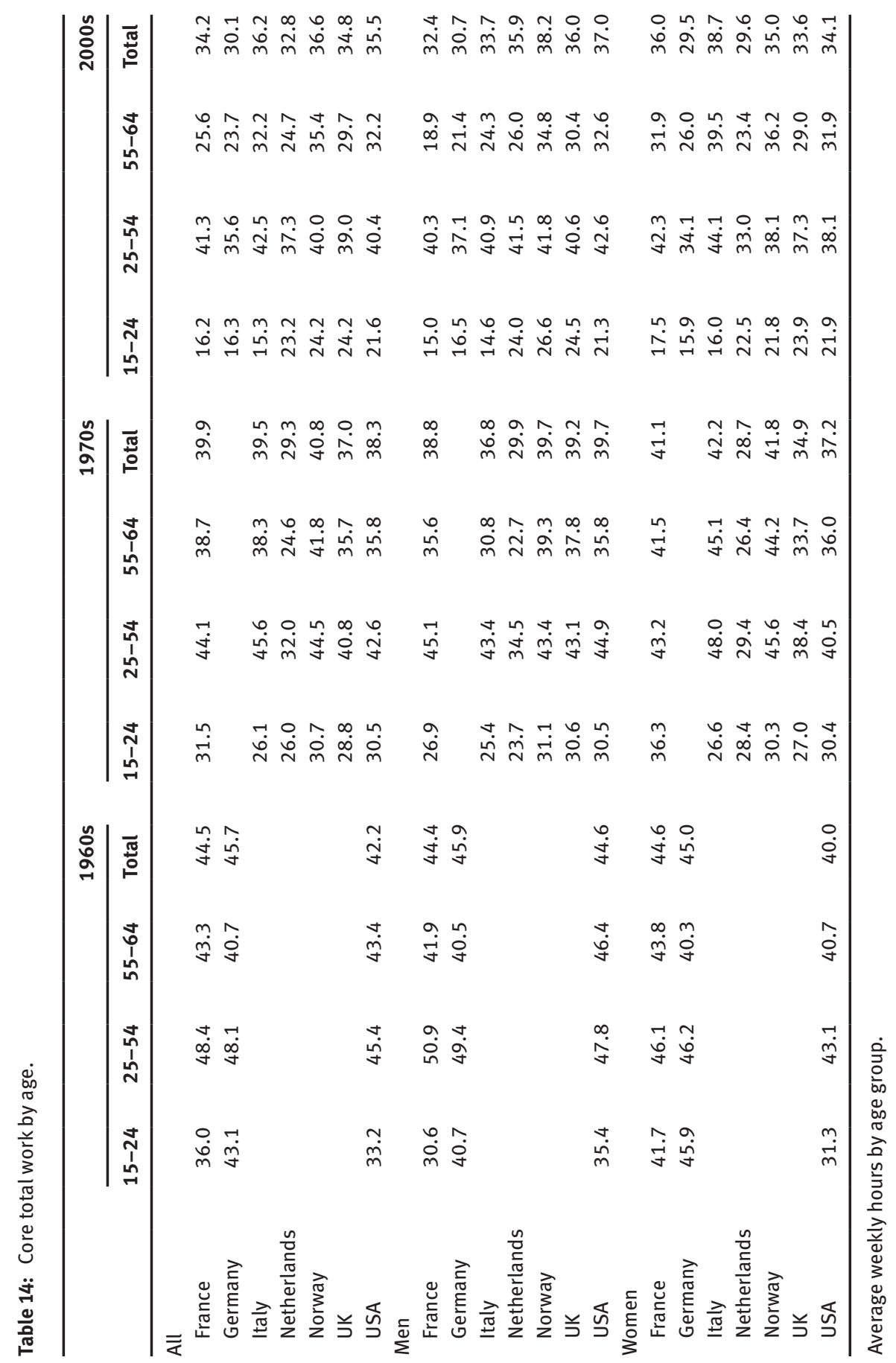


Gimenez-Nadal and Sevilla (2012), we construct measures of time allocation with the constant demographic weighting scheme. As discussed above, the estimates based on the constant demographic weighting scheme do not allow for a meaningful cross-country comparison of time allocation levels. Hence, this section focuses on the comparison of the trend changes in time allocation from the two weighting schemes.

The constant demographic weighted estimates exhibit similar trend movements as the reported estimates in market hours, home hours, and child care hours by gender. ${ }^{26}$ Specifically, the estimates deliver an increase in female market hours, male home hours, and child care hours of both genders and also deliver a decrease in female home hours and male market hours. More importantly, the decrease in female home hours is also larger than the increase in male home hours under the constant demographic weighting scheme. Hence, the estimates also reaffirm the declining trend in home hours per person and the importance of female home hours in driving the declining trend in home hours per person. A detailed comparison of our estimates with the constant demographic weighted estimates is available in the web Appendix A.

\section{Conclusion}

This paper constructed market hours, home hours, and total hours for the US and several European countries. Three findings emerge from the data. First, home hours have declined in both the US and European countries over the past 50 years. Second, female time allocation contributes more to the cross-country difference than does male time allocation. Third, the time allocation of non-primeage individuals is more different across countries than is the time allocation of prime-age individuals.

Men have decreased their market hours and increased their home hours, and women have increased their market hours and decreased their home hours. The changes lead to the reduction in the gaps of both market hours and home hours between men and women. Most of the decrease in female home hours is shifted to market hours. The increase in female market hours is mainly due to the increase in the female labor force participation rate. As discussed in Section 1.1,

26 The market hours for women in France and Italy and for men in the Netherlands display trends with the opposite sign when estimated using constant demographic weights. 
the improvement in home production productivity and changes in cultural and social norms have been identified as potential causes of the increase in the female labor force participation rate. The increase in male home hours is likely because women devote less time to home work and thus men must take on more responsibilities at home. It may be also related to changes in attitudes toward men's performing more housework.

The existing models that study the difference in time allocation between the US and Europe mainly focus on time allocation per person and market hours by sector. ${ }^{27}$ This paper suggests that it is also of interest to include gender and/or age in the model and then use the model to explore the factors that can account for the cross-country difference in time allocation by demographic groups. One interesting question to ask is whether institutional differences, such as differences in tax systems, labor laws or social welfare programs, can account for the cross-country differences in time allocation by demographic groups. For instance, higher tax rates in European countries may be more harmful to the market labor supply of women because women are less attached to the labor market than men.

The cross-country difference in time allocation by age is mainly driven by the difference in the employment to population ratio by age. The employment to population ratio is much lower for the young and old groups in European countries than it is in the US. This phenomenon may be related to the more generous welfare programs and/or the more rigid labor market regulations in Europe. For instance, more generous retirement benefits may contribute to the low employment to population ratio of old Europeans. The more generous unemployment insurance benefits and the more rigid labor market regulations may contribute to the low employment to population ratio of young Europeans. We leave these questions for future research.

Acknowledgments: We thank Richard Rogerson and seminar participants of the 2011 Midwest Macroeconomics Meetings, and the 2011 Computing in Economics and Finance Meetings. We also thank the editor, Tiago Cavalcanti, and one anonymous referee for their comments and suggestions. The views expressed here are the opinions of the authors only and do not necessarily represent those of the Federal Reserve Bank of Atlanta or the Federal Reserve System.

27 See, for example, Ragan (2013), Rogerson (2008), Ngai and Pissarides (2008), Ngai and Pissarides (2011), and McDaniel (2011). 


\section{References}

Aguiar, Mark, and Erik Hurst. 2007. "Measuring Trends in Leisure: The Allocation of Time Over Five Decades.” Quarterly Journal of Economics 122 (3): 969-1006.

Alexopoulos, Joanna, and Tiago V. Cavalcanti. 2010. “Cheap Home Goods and Persistent Inequality." Economic Theory 45: 417-451.

Benhabib, Jess, Richard Rogerson, and Randall Wright. 1991. "Homework in Macroeconomics: Household Production and Aggregate Fluctuations.” Journal of Political Economy 99 (6): $1166-1187$.

Bianchi, Suzanne M. 2000. “Maternal Employment and Time with Children: Dramatic Change or Surprising Continuity?” Demography 37 (4): 401-414.

Bianchi, Suzanne M., Melissa A. Milkie, Liana C. Sayer, and John P. Robinson. 2000. "Is Anyone Doing the Housework? Trends in Gender Division of Household Labor.” Social Forces 79 (1): 191-228.

Burda, Michael C., Daniel S. Hamermesh, and Philippe Weil. 2008. "The Distribution of Total Work in the EU and USA." Working Hours and Job Sharing in the EU and USA. Oxford University Press.

Burda, Michael C., Daniel S. Hamermesh, and Philippe Weil. 2013. “Total Work and Gender: Facts and Possible Explanations.” Journal of Population Economics 26: 239-261.

Campbell, John Y., and Sydney Ludvigson. 2001. "Elasticities of Substitution in Real Business Cycle Models with Home Protection." Journal of Money, Credit and Banking 33 (4): 847-875.

Cavalcanti, Tiago V., and Jose Tavares. 2008. "Assessing the "Engines of Liberation": Home Appliances and Female Labor Force Participation." The Review of Economics and Statistics 90 (1): 81-88.

Cavalcanti, Tiago V., and Jose Tavares. 2011. "Women Prefer Larger Governments: Growth, Structural Transformation, and Government Size." Economic Inquiry 49 (1): 155-171.

Costa, Dora L. 2000. “From Mill Town to Board Room: The Rise of Women's Paid Labor.” The Journal of Economic Perspectives 14 (4): 101-122.

Fernandez, Raquel. 2013. "Culture Changer as Learning: The Evolution of Female Labor Force Participation over a Century.” American Economic Review 103 (1): 472-450.

Fogli, Alessandra, and Laura Veldkamp. 2011. "Nature or Nurture? Learning and the Geography of Female Labor Force Participation." Econometrica 79 (4): 1103-1138.

Freeman, Richard B., Ronald Schettkat, Esther Duflo, and Tullio Jappelli. 2005. "Marketization of Household Production and the EU-US Gap in Work." Economic Policy 20 (41): 5-50.

Galor, Oded, and David Weil. 1996. "The Gender Gap, Fertility, and Growth.” American Economic Review 86 (3): 374-387.

Gauthier, Anne H., Timothy M. Smeeding, and Frank F. Furstenberg. 2004. "Are Parents Investing Less Time in Children? Trends in Selected Industrialized Countries." Population and Development Review 30 (4): 647-671.

Gimenez-Nadal, Jose Ignacio, and Almudena Sevilla. 2012. "Trends in Time Allocation: A CrossCountry Analysis." European Economic Review 56 (6): 1338-1359.

Goldin, Claudia. 1990. Understanding the Gender Gap: An Economic History of American Women. New York: Oxford University Press.

Greenwood, Jeremy, and Zvi Hercowitz. 1991. "The Allocation of Capital and Time Over the Business Cycle.” Journal of Political Economy 99 (6): 1188-1214.

Greenwood, Jeremy, Ananth Seshadri, and Mehmet Yorukoglu. 2005. "Engines of Liberation.” Review of Economic Studies 72 (1): 109-133. 
Greenwood, Jeremy, Nezih Guner, and Guillaume Vandenbroucke. Forthcoming. "Family Economics Writ Large." Journal of Economic Literature.

Guryan, Jonathan, Erik Hurst, and Melissa Kearney. 2008. "Parental Education and Parental Time with Children." Journal of Economic Perspectives 22 (3): 23-46.

Heathcote, Jonathan, Kjetil Storesletten, and Giovanni L. Violante. 2010. "The Macroeconomic Implications of Rising Wage Inequality in the United States.” Journal of Political Economy 118 (4): 681-772.

Kahneman, Daniel, and Alan B. Krueger. 2006. "Developments in the Measurement of Subjective Well-Being.” Journal of Economic Perspectives 20 (1): 3-24.

McDaniel, Cara. 2011. "Forces Shaping Hours Worked in the OECD, 1960-2004." American Economic Journal: Macroeconomics 3 (4): 27-52.

McGrattan, Ellen R., and Richard Rogerson. 2004. “Changes in Hours Worked, 1950-2000.” Quarterly Review, Federal Reserve Bank of Minneapolis 28 (1): 14-33.

McGrattan, Ellen R., Richard Rogerson, and Randall Wright. 1997. "An Equilibrium Model of the Business cycle with Household Production and Fiscal Policy." International Economic Review 38 (2): 361-381.

Ngai, L. Rachel, and Christopher A. Pissarides. 2008. "Trends in Hours and Economic Growth." Review of Economic Dynamics 11 (2): 239-256.

Ngai, L. Rachel, and Christopher A. Pissarides. 2011. "Taxes, Social Subsidies, and the Allocation of Work Time." American Economic Journal: Macroeconomics 3 (4): 1-26.

Ngai, Rachel, and Barbara Petrongolo. 2014. "Gender Gaps and the Rise of the Service Economy." Working Paper.

Ohanian, Lee, Andrea Raffo, and Richard Rogerson. 2008. "Long-Term Changes in Labor Supply and Taxes: Evidence from OECD Countries, 1956-2004." Journal of Monetary Economics 55 (8): 1353-1362.

Ragan, Kelly. 2013. "Taxes and Time Use: Fiscal Policy in a Household Production Model.” American Economic Journal: Macroeconomics 5 (1): 168-192.

Ramey, Valerie A. 2009. "Time Spent in Home Production in the Twentieth-Century United States: New Estimates from Old Data." Journal of Economic History 69 (1): 1-47.

Ramey, Valerie A., and Neville Francis. 2009. "A Century of Work and Leisure." American Economic Journal: Macroeconomics 1 (2): 189-224.

Ramey, Garey, and Valerie A. Ramey. 2010. "The Rug Rat RaceComments and Discussion.” Brookings Papers on Economic Activity 41 (1): 129-176.

Rogerson, Richard. 2008. "Structural Transformation and the Deterioration of European Labor Market Outcomes." Journal of Political Economy 116 (2): 235-259.

Sayer, Liana C., Suzanne M. Bianchi, and John P. Robinson. 2004. "Are Parents Investing Less in Children? Trends in Mothers and Fathers Time with Children." American Journal of Sociology 110 (1): 1-43.

Sevilla, Almudena, Jose I. Gimenez-Nadal, and Jonathan Gershuny. 2012. "Leisure Inequality in the United States: 1965-2003." Demography, 49(3): 939-964.

Supplemental Material: The online version of this article (DOI: 10.1515/bejm-2015-0031) offers supplementary material, available to authorized users. 